\title{
RESULTS AND PERSPECTIVES IN IMPLEMENTING REGIONAL OPERATIONAL PROGRAM
}

\author{
Ionela Gavrila-Paven \\ 1 Decembrie 1918 University of Alba Iulia, Romania \\ ionelapaven@yahoo.com
}

\begin{abstract}
Increasing the efficiency of structural funds and the rate of absorption is one of the opportunity that Romanian economy has to maximize. The article presents a general analysis on the absorption of Regional Operational Program for the financial programming period 2007-2013. This evolution is being regarded in the context of improving the efficiency of the Regional Operational Program for the present financial programming period 20142020 , in order to use the experience accumulated and to increase the absorption rate.
\end{abstract}

Keywords: Regional Operational Program, structural funds, economic performance, regional development strategies.

JEL Classification: $L 15, P 17$

\section{Introduction}

Romania, as a member state of the European Union since 2007, has assumed a national development policy that ensures convergence with Community policies, objectives, principles and regulations, in order to ensure a balanced socio-economic development leading towards reducing development gaps with the European Union (Blom-Hansen, J., 2015; Caldas, P. et al., 2018). The framework documents underlying this policy are the National Strategy of Romania and the National Development Plan, two strategic documents focused on a balanced development and on the diminishing of development gaps compared to the European Union.

Community policies that support balanced development at European Union level are implemented at Member State level through specific funds and programs, adjusted to the particularities of each Member State (Coppola, G. et al. 2020; Crescenzi, R. et al. 2020). The National Strategic Reference Framework established at national level, is structured on specific thematic priorities and aims at developing the basic infrastructure at European standards, ensuring the interconnectivity of the European space, the objective being to develop a stable and attractive environment for those who want to live, work and invest here (Hagemann, C., 2019; Pîrvu, Ramona et al. 2018).

Differences and gaps in economic development are also found between regions at national level. These development gaps have been the basis for drawing up a regional development strategy aimed at promoting balanced territorial development. These strategies aim to respond to the needs of territorial development, focusing on a coherent development of investments and planned strategic actions (Fiaschi, D. et al. 2018). The long-term strategic objective in terms of regional development is to affirm the regional and European identity of our country, which has a major role in ensuring European interconnectivity but also a bridge between Europe and Asia (Incaltarau, C. et al. 2020; Kersan-Škabi'c et al. 2017).

At the level of the national economy there can be identified a series of generalized problems at the regional level, which determine an unequal development in the territorial plan: (1) the relatively large number of subsistence and semi-subsistence farms, with average areas less than 2 ha; (2) low productivity in agriculture, due to lack of financial resources, inefficient use of existing resources, lack of qualified staff in modern agricultural practices, lack of 
managerial and marketing skills, all doubled by poor infrastructure; (3) the significant gap between the import and export of agricultural products; (4) the lack of organized trade chains for agricultural producers, as they are not represented by specific bodies; (5) poor basic infrastructure; (6) large areas of land affected by natural risk factors such as floods, earthquakes and landslides, desertification and insufficient water sources.

These development problems identified at the regional level become even more obvious when we compare the rural and the urban environment, unlike the European countries where the transition from urban to rural area is almost insignificant. To solve these problems, the European Regional Development Fund was created at European level. In Romania this fund can be accessed through the Regional Operational Program. The main objective of the Regional Operational Program is to accelerate the economic growth of disadvantaged regions, aiming that the development gap between the best developed and the least developed Region, in terms of Gross Domestic Product not to increase in the programming period, compared to the present situation. In order to make the best use of structural instruments and in compliance with Community policy objectives, each Member State has an obligation to monitor, evaluate and control expenditure from the Structural Funds and to publish data on the state of implementation of these programs (Herta Todtling̈Schonhofer," et al. 2014; Jurgen̈Pucher, et al. 2015).

The Regional Operational Program 2007 - 2013 had as specific objectives: (1) increasing the economic and social role of urban centres through a polycentric approach; (2) improving the accessibility of regions, in particular urban centres and their links; (3) increasing the quality of the social infrastructure of the regions; (4) increasing the competitiveness of regions as business locations; (5) increasing the contribution of tourism to the development of the regions. In comparison, the current Regional Operational Program $2014-2020$ aims at: (1) promoting technology transfer; (2) improving the competitiveness of small and medium enterprises; (3) supporting the transition to a low-carbon economy; (4) supporting sustainable urban development; (5) improving the urban environment and preserving, protecting and sustainably capitalizing on cultural heritage; (6) improving road infrastructure of regional importance; (7) diversification of local economies through sustainable development of tourism; (8) development of health and social infrastructure; (9) supporting the economic and social regeneration of disadvantaged communities in urban areas; (10) improving educational infrastructure; (11) the geographical extension of the system of registration of properties in cadastre and land book and (12) technical assistance (Romanian Govern 2007, 2015).

The general aim of the program is to contribute to reducing regional disparities as well as disparities within regions, between urban and rural areas, between urban centres and neighbouring rural areas, respectively even within cities, between more developed areas, more attractive to investors and unattractive areas, making better use of regional synergies. Thus, a balanced development of all regions of the country is pursued, possible through an integrated approach, combining public investment in local infrastructure with active policies to stimulate investment and capitalize on local resources.

\section{Regional Operational Program - regional objectives}

The general objective of the Regional Operational Program is to ensure a balanced economic and social development at territorial and sustainable level, for all regions of Romania, by developing infrastructure and business environment that meet the needs and capitalize on specific resources within each development region.

Development strategies implemented at regional level give priority to lagging regions and areas that are deficient in terms of development, infrastructure and need public support and intervention to deal with the negative consequences of development trends, and not to contribute to the deepening of the existing development gaps. The strategic vision of the 
Regional Operational Program in terms of balanced territorial development is based on the following elements: (1) the importance of balanced development of all regions by recognizing the urban dimension, respectively the development of urban development poles and the area in their immediate vicinity; (2) the development of higher urban functions in order to create a critical mass that will generate demand for services and stimulate more and more post-industrial activities; (3) promoting a bottom-up approach, starting from local development needs, not from the national level; (4) ensuring the preconditions for economic growth, namely the development of local and regional infrastructure on which to achieve growth and, subsequently, economic development; (5) ensuring accessibility, including to mountain areas, respectively to and within congested urban areas; (6) attracting back to the region the Romanian emigrants and avoiding the economic isolation of the disadvantaged regions or areas; (7) capitalizing on local resources through a balanced development, including the tourist potential.

The purpose of the Regional Operational Program is to contribute to the achievement of the strategic objective of ensuring a balanced development by complementing national sectoral interventions and actions with regional and interregional specificity in order to ensure and support economic growth. The Regional Operational Program supports all actions aimed at improving safety standards, reducing negative effects on the environment, reducing climate change, protecting transport infrastructure from natural disasters, and eliminating dangerous traffic points.

In order to contribute to the achievement of the objectives of the Europe 2020 Strategy for smart, sustainable and inclusive growth, the new framework in which the Regional Operational Program is implemented has the following thematic objectives:

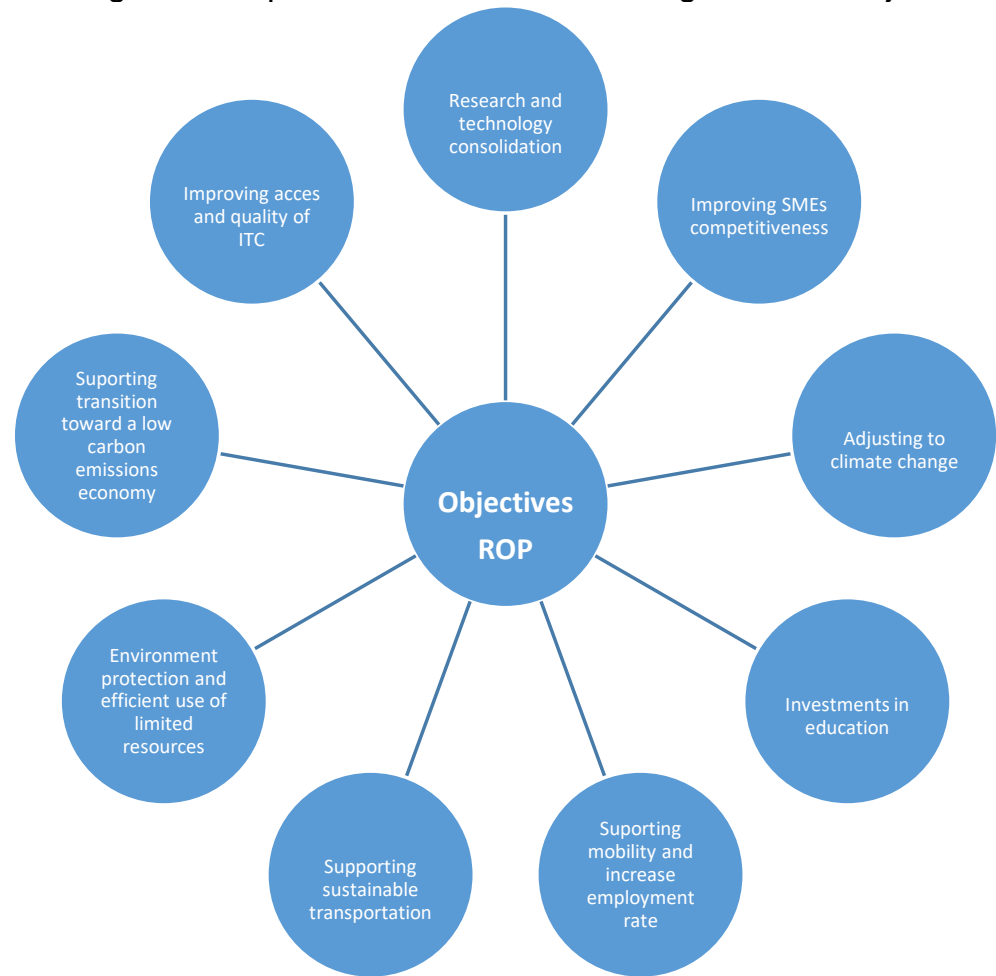

Figure 1: Objectives for Regional Operational Program 


\section{Achieved results and perspectives in implementing Regional Operational Program}

The results obtained in implementing Regional Operational Program 2007 - 2013 can be analyzed, respectively valorized by improving the absorption process for current financial program, $2014-2020$ and for the next. The value of community funds (European Regional Development Fund) allocated for the Regional Operational Program for the period 20072013 was $3,966,021,762$ euros. Conclusions can be drawn by analyzing the entire process. Thus, considering the end of October 2016 the stage of implementation for Regional Operational Program was as follows:

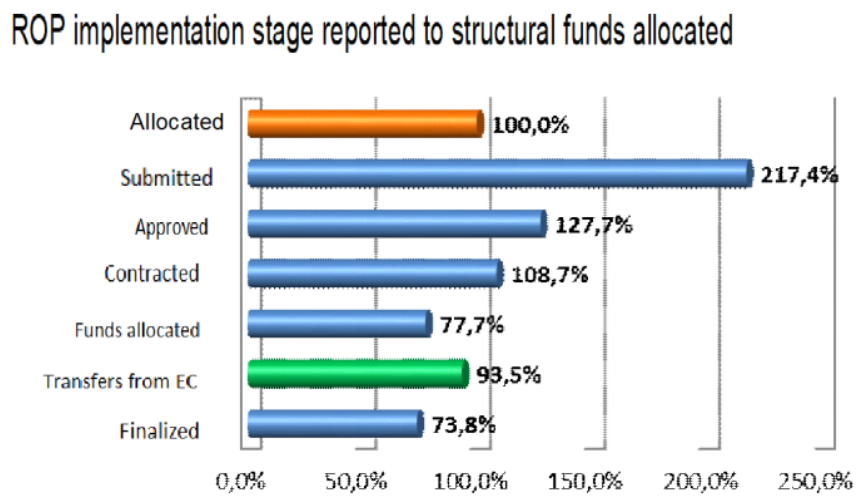

Figure 2: Regional Operational Program 2007 - 2013 implementation stage reported to structural funds allocated

Source: Evaluation Report, Interventions Evaluation ROP 2007-2013, 2019.

Implementing the 4,491 projects completed by March 15, 2017, there were created 24,994 jobs. By the same date, there were 10,056 financing applications submitted requesting approximatively 8.62-billion-euro contribution from the European Regional Development Fund, representing $217 \%$ of the European Regional Development Fund allocation related to the Regional Operational Program.

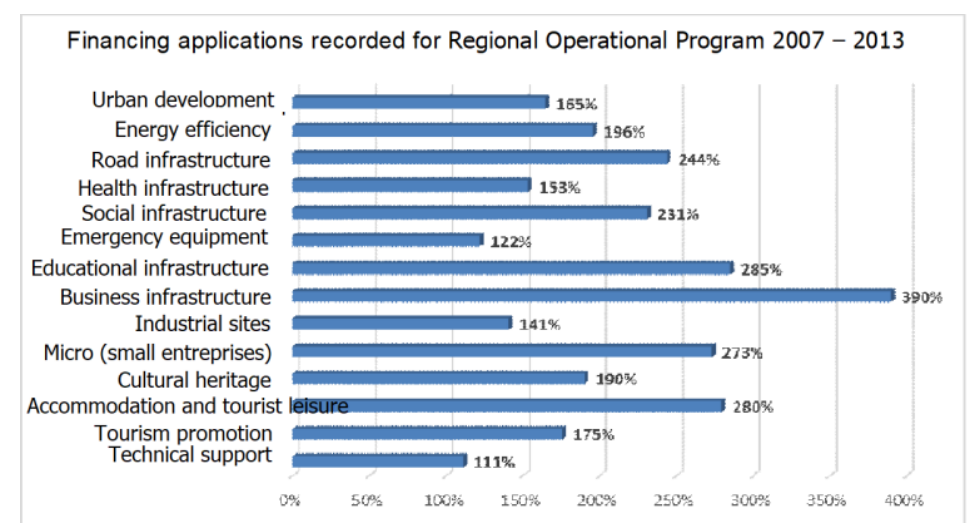

Figure 3: Financing applications recorded for Regional Operational Program 2007 - 2013 at March 15, 2017

Source: Evaluation Report, Interventions Evaluation ROP 2007-2013, 2019. 
At the same moment there were 4,491 completed projects, with a total eligible value of 3.67 billion euros, of which the European Regional Development Fund contribution was 2.93 billion euros (representing $74 \%$ of the European Regional Development Fund allocation of the Regional Operational Program).

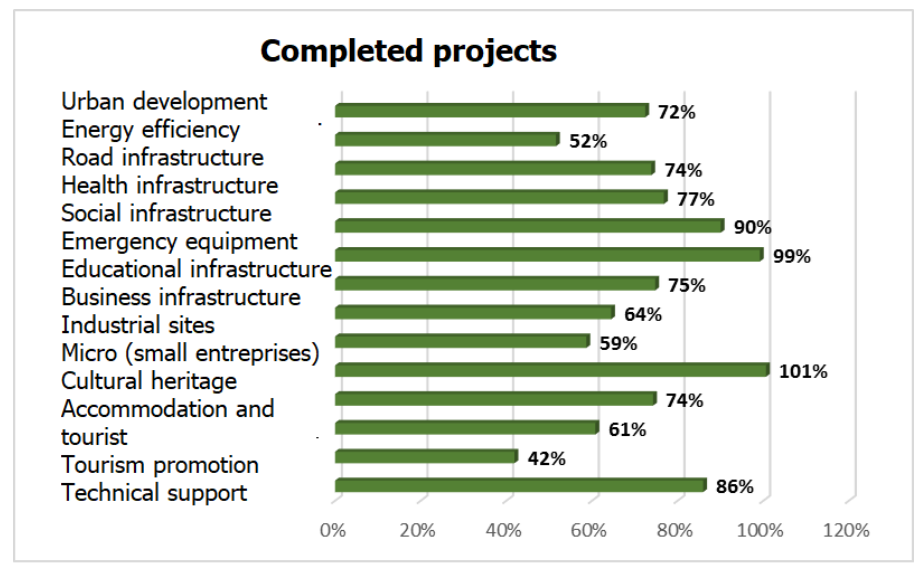

Figure 4: Completed projects implemented from Regional Operational Program 2007 2013 at March 15, 2017

Source: Evaluation Report, Interventions Evaluation ROP 2007-2013, 2019.

Compared to 2014 , there is a $68 \%$ increase in the number of completed projects and a $123 \%$ increase in the European Regional Development Fund contribution to completed projects, from 1.3 billion euros in 2014 to 2.93 billion euros in March 2017.

At the level of domains, the advance over the average of the program registered by the field of emergency equipment, micro-enterprises and social infrastructure is noticeable.

\section{Projects completed by regions}

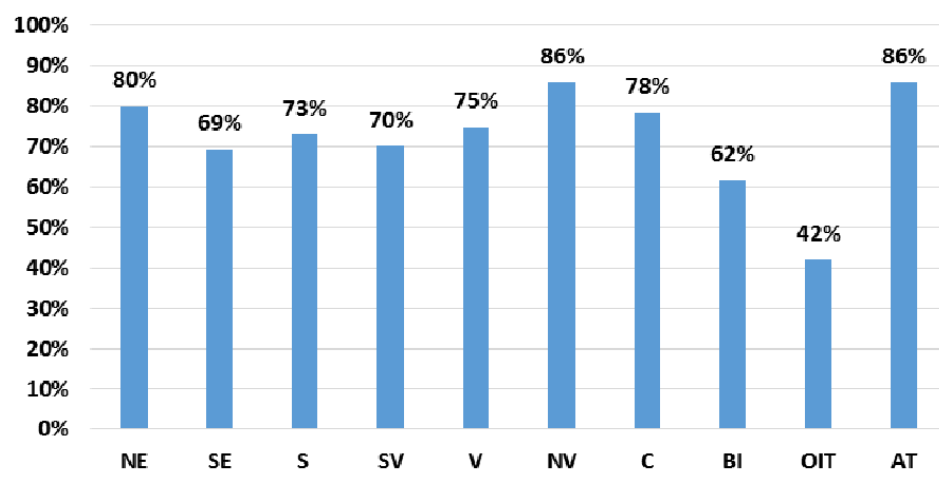

Figure 5: Completed projects implemented from Regional Operational Program 2007 2013 by regions at March 15, 2017

Source: Evaluation Report, Interventions Evaluation ROP 2007-2013, 2019.

At the regional level, the North-West, North-East and Central regions stand out, given that all regions recorded values of over $60 \%$. 
Table 1. Financial allocation from Regional Operational Program

\begin{tabular}{|l|c|c|c|c|c|}
\hline \multicolumn{1}{|c|}{ Objective } & $\begin{array}{c}\text { Total } \\
\text { financial } \\
\text { allocation }\end{array}$ & $\begin{array}{c}\text { Basis } \\
\text { calculation } \\
\text { for } \\
\text { European } \\
\text { contributio } \\
\text { n (public) }\end{array}$ & $\begin{array}{c}\text { Certificated } \\
\text { expenditures }\end{array}$ & $\begin{array}{c}\text { Public } \\
\text { contribution }\end{array}$ & $\begin{array}{c}\text { Certificate } \\
\text { d rate (\%) }\end{array}$ \\
\hline $\begin{array}{l}\text { Urban } \\
\text { developmen } \\
\text { t }\end{array}$ & $\begin{array}{c}1.438 .989 .38 \\
0\end{array}$ & public & $\begin{array}{c}1.236 .173 .329,6 \\
6\end{array}$ & $\begin{array}{c}1.236 .173 .329,6 \\
6\end{array}$ & $85,91 \%$ \\
\hline $\begin{array}{l}\text { Road } \\
\text { infrastructur } \\
\mathbf{e}\end{array}$ & 952.105 .021 & public & $797.627 .591,39$ & $797.627 .591,40$ & $83,78 \%$ \\
\hline $\begin{array}{l}\text { Social } \\
\text { infrastructur } \\
\mathbf{e}\end{array}$ & 864.474 .865 & public & $739.396 .046,21$ & $738.900 .182,02$ & $85,47 \%$ \\
\hline $\begin{array}{l}\text { Business } \\
\text { infrastructur } \\
\mathbf{e}\end{array}$ & 561.685 .142 & public & $593.957 .676,21$ & $504.886 .013,44$ & $89,89 \%$ \\
\hline $\begin{array}{l}\text { Tourism } \\
\text { developmen } \\
\mathbf{t} \\
\text { promotion }\end{array}$ & 717.378 .873 & public & $624.415 .460,31$ & $571.896 .611,04$ & $79,72 \%$ \\
\hline $\begin{array}{l}\text { Technical } \\
\text { assistance }\end{array}$ & 131.506 .650 & public & $115.869 .083,55$ & $115.869 .083,55$ & $88,11 \%$ \\
\hline Total & $\mathbf{4 . 6 6 6 . 1 3 9 . 9 3}$ & public & $\begin{array}{c}\mathbf{4 . 1 0 7 . 4 3 9 . 1 8 7 , 3} \\
\mathbf{3}\end{array}$ & $\mathbf{3 . 9 6 5 . 3 5 2 . 8 1 1 , 1}$ & $84,98 \%$ \\
\hline
\end{tabular}

Source: Evaluation Report, Interventions Evaluation ROP 2007-2013, 2019.

Note: Some of the amounts included in the final payment application were certified under reservation.

Cohesion policy covers all European Union states and each region. However, according to the rules of allocation, most funds are concentrated in regions with a Gross Domestic Product (GDP) per capita below $75 \%$ of the European Union average. Reducing disparities between regions is an objective that can be achieved through the mechanism of financial allocations implemented through the Regional Operational Program. Regional analysis shows discrepancies also at regional level. Regional strategies aim to reduces these disparities within a region, but there are still certain limits to action, depending in particular on the demographic level of each region. Furthermore, the regional policy framework is being established at national level, and implemented at regional level, so the instruments are not particularized depending on the regional specificities.

The small and medium enterprises sector remains a strategic sector for Romanian economy. In the context of last years, is extremely important to provide financial and nonmonetary assistance to SMEs in order to reduce the large differences in economic competitiveness compared to the European average. The efforts should be focused on increasing labor productivity through reducing technological gap, that will contribute to the diminishing of production costs. Also, this program represents an opportunity for SMEs to invest and support the innovation process in sectors with regional development potential. SMEs can obtain support regarding the participation on the EU internal market, the development of exports. Regional Operational Program is promoting also the concept of circular economy and the involvement of SMEs in international research, development and innovation projects. 
Depending on the category to which SMEs belong, they have distinct needs. Therefore, it had to be considered to adapt the types of support according to these different needs. Thus, the conclusion is that the Regional Operational Program proposes financing solutions based on the distinct needs of SMEs. Equally, the Regional Operational Program is only one of the financial instruments for implementing public policies to support the development of SMEs and cannot come up with financing solutions for absolutely all the problems of all SMEs in all sectors of the Romanian economy, given the restrictions brought by conditions in implementing European Structural and Investment Funds (ESF), but also the limit of the available budget.

Romanian SMEs have access to all existing sources of financing in the market under the conditions established by the respective programs and sources of financing based on the financing priorities and the principle of ensuring complementarity. The Regional Operational Program is the only operational program, which for the 2014-2020 financing period supports investments for improving the competitiveness of small and medium-sized enterprises, the agricultural sector and the fisheries and aquaculture sector. This objective was developed based on the results achieved for the $2007-2013$ programming period. This is the reason to continue the analyze of the economic performances of SMEs that have implemented projects for business development even after the sustainability period. This analyze should be conducted also on economic sectors and to compare the results obtained by this SMEs. The institutional system for coordination, management and control of the ROP 2014-2020 has made efforts to apply a more standardized and, at the same time, more simplified approach to the submission, evaluation, contracting, monitoring and control processes. This approach focused on the needs and response capacities of the target group of beneficiaries. This standardization aims to diminish the bureaucracy in project management, but in the same time underlines the SMEs needs to have specialized employees, which will implement the projects.

The partnership principle was very well implemented in the programming phase and requires follow-up in the implementation stage as well. Both the documentation carried out at the level of international practices and the field findings show that we can improvement the implementation of the partnership principle. This partnership principle assures the visibility of the projects and the results obtained in implementation, allowing to the partners to exchange good practices and also to collaborate. This concept of partnership can change the SMEs behavior from competition to cooperation and collaboration, if it is implemented in real activity. Still, there is the risk that the involvement of partners was only a formalist exercise, usually done to obtain high score in evaluation stage of projects.

Challenges for the future: SMEs sector needs a public policy to support the internationalization of the activity of the business sector on multiple levels and directions of action. The existing public policy is being focused on promoting export activities and its results are far from being efficient. Regional initiatives and subsequent financial instruments to support the internationalization of SMEs cannot go beyond the national regulatory framework. Therefore, strictly consistent with the regulations underlying the use of the FESI, the ROP's intervention in this area is limited to support measures to improve economic competitiveness in order to stimulate exports as a first step in the internationalization strategy.

\section{In conclusion}

Regarding the achievements obtained in phases of the implementation cycle, the main conclusions resulting from the analysis are: (1) communication improvement: introduction of the help desk information and support offices. There was developed desk information 
departments in order to assure the support of the applicants, including during the clarification period. Still, remains the need to improve the operational procedure, training and introduction of a mechanism for exchanging experience and lessons learned in the communication relationship with SMEs and other categories of program beneficiaries; (2) increased quality of the guidelines specific to the various calls - the corrections that have been made and the improvement of the guidelines prove that it is a learning process that the implementation system is still going through with the understanding of the specifics of the SMEs sector that it being financed; (3) implementation of an application special designed to respond horizontally to all operational programs whose source of funding is FESI, eliminating physical documentation in sending a project proposal for evaluation, as well as for implementing projects. The application assures increased transparency in the management and use of FESI. Therefore, it is an "asset" of the operational programs that needs to be maintained and improved, into a modernized formula that better meets the specifics of the Regional Operational Program.

Within the current financial programming period, new types of financing instruments are proposed, namely: (1) the joint action plan - represents a group of implemented projects, which are in the responsibility of the beneficiary, this being seen as part of the program; (2) integrated territorial investment - represents an integrated approach of urban or territorial development strategies that involves investments made from several priority axes, being able to combine financial assistance from one or more operational programs; (3) local development placed under the responsibility of the community - is a way of development achieved through local development strategies, these strategies are developed on integrated and multisector areas, being placed under the responsibility of the community, respectively Local Action Groups, groups that bring together representatives of local socioeconomic interests from both the public and private sectors; Local Action Groups are responsible with the development and implementation of local development strategies.

The objectives of Regional Operational Program should be reconsidered in the framework of pandemic influences upon different economic sectors. This approach could help SMEs to reconsider the productive fluxes and to adjust their offer to the tendencies recorded on the market demand and their activity to current restrictions and conditions.

\section{Acknowledgements}

This paper is part of the research conducted in the Contract for Post-Doctorate Studies, University Studies No Scholarship No. 221/5 / 01.11.2019, Improving the economic and financial performance of enterprises by accessing non-reimbursable funds. Case study Regional Operational Program 2007-2013, Romanian Academy, Institute of National Economy, Bucharest, Romania.

\section{References}

1. Blom-Hansen, Jens. 2015. Principals, agents, and the implementation of EU cohesion policy. Journal of European Public Policy 12: 624-48.

2. Caldas, Paulo, Brian Dollery, and Rui Cunha Marques. 2018. European Cohesion Policy impact on development and convergence: A local empirical analysis in Portugal between 2000 and 2014. European Planning Studies 26: 1081-98.

3. Coppola, Gianluigi, Sergio Destefanis, Giorgia Marinuzzi, and Walter Tortorella. 2020. European Union and nationally based cohesion policies in the Italian regions. Regional Studies 54: 83-94.

4. Crescenzi, Riccardo, and Mara Giua. 2020. One or many Cohesion Policies of the European Union? On the differential economic impacts of Cohesion Policy across member states. Regional Studies 54: 10-20. 
5. Fiaschi, Davide, Andrea Mario Lavezzi, and Angela Parenti. 2018. Does EU cohesion policy work? Theory and evidence. Journal of Regional Science 58: 386-423.

6. Hagemann, Christian. 2019. How politics matters for EU funds' absorption problems-A fuzzy-set analysis. Journal of European Public Policy 26: 188-206.

7. Incaltarau, Cristian, Gabriela Carmen Pascariu, and Neculai-Cristian Surubaru. 2020. Evaluating the Determinants of EU Funds Absorption across Old and New Member States-The Role of Administrative Capacity and Political Governance. Journal of Common Market Studies.

8. Pîrvu, Ramona, Roxana Bădîrcea, Alina Manta, and Mihaela Lupăncescu. 2018. The Effects of the Cohesion Policy on the Sustainable Development of the Development Regions in Romania. Sustainability 10: 2577.

9. Kersan-Škabi'c, Ines, and Lela Tijani'c. 2017. Regional absorption capacity of EU funds. Economic Research - Ekonomska Istraživanja 30: 1191-208.

10. ETUC, BUSINESSEUROPE and UEAPME, Implementation of the European code of conduct on partnership, March 2015

11. Herta Todtling̈-Schonhofer," et al., Metis GmbH, John Bachtler, et al., EPRC University, Implementation of Cohesion Policy 2014-2020: Preparation and Administrative capacity of Member States, European Parliament, Policy Department for Structural and Cohesion Policies, 2014.

12. Jurgen̈Pucher, et al., Metis GmBH, Review of the Adopted Partnership Agreements, European Parliament, Policy Department for Structural and Cohesion Policies, 2015

13. Guvernul României, Programul Operațional Regional 2007-2013, București, 2007.

14. Guvernul României, Programul Operațional Regional 2014-2020, București, 2015.

15. Raport de evaluare, Evaluarea intervențiilor POR 2014-2020, București, 2019.

16. Programul Operaţional Regional 2007-2013, Raportul Final de Implementare 2007-2013, Martie 2017. 